\title{
Anthós
}

\section{Veteran Literacy: A Case for Veteran Identity Theory in Composition and Literature}

Devin Whitaker

Portland State University

Follow this and additional works at: https://pdxscholar.library.pdx.edu/anthos

Part of the English Language and Literature Commons Let us know how access to this document benefits you.

\section{Recommended Citation}

Whitaker, Devin (2014) "Veteran Literacy: A Case for Veteran Identity Theory in Composition and Literature," Anthós: Vol. 6: Iss. 1, Article 10.

https://doi.org/10.15760/anthos.2014.151

This open access Article is distributed under the terms of the Creative Commons Attribution-NonCommercialShareAlike 4.0 International License (CC BY-NC-SA 4.0). All documents in PDXScholar should meet accessibility standards. If we can make this document more accessible to you, contact our team. 


\title{
Veteran Literacy: A Case for Veteran Identity Theory in Composition and Literature
}

\author{
Devin Whitaker
}

\section{Preface}

What began as a Composition Theory paper about today's veterans in the higher-ed. composition classroom quickly turned into something much larger. When I began, I was responding to ways in which veteran students come into early composition courses with preexisting writing skills from their time in the armed forces. As my research progressed I discovered a variety of ways by which veteran students are perceived and labeled upon entering the educational institution, as well as society at large, that vastly separate them from their academic peers but regard the veteran student as possessing a deficit or handicap to overcome. While my experience as a veteran can confirm that there are many obstacles in the service-to-civilian-tostudent transition, I would also add that many of the commonly held perceptions of veterans are inaccurate and become yet another hurdle for veteran students to negotiate.

Ultimately what came out of my research was a foundational argument for ways by which veterans come to read and interpret the world around them after leaving the armed forces and how they will continue to create meaning through the lens of their experience, both individually and as a distinguished group. Very little has been written on this subject and so the bulk of my evidence relies heavily upon the Fall 2013 issue of Composition Forum, which focuses entirely on veteran students in composition. As the narrative progressed it became apparent that the scope of the ideas I had begun to scratch the surface of was so large that one could dedicate 
their entire life to their study and still not entirely realize their impact. The infancy of these ideas as well as their need for continued discourse cannot be over-emphasized. Their ambition, however, could lay the groundwork for something new within the humanities. My hope for this essay and supplementary writing exercises is that the broad ideas they serve as a jumping-off point for specific scholarship addressing the need for a conversation to begin and to sustain regarding veterans and what they can contribute to the humanities, literature theory and composition course instruction.

\section{Introduction}

Veteran students bring a diverse set of professional, educational and personal literacies to the academic institution. Many of the issues facing the veteran student in today's academic environment, however, are in identifying the relevance of their literacies, applying these literacies to the expectations of the institution, learning to negotiate multiple instructor expectations, and lack, however, of instructor input. For each level of the military induction literacy process there are protocols, expected outcomes, and documentable assessments which render veteran students among the most accessible and applicable subjects for rethinking their capacity for reading, interpreting and creating meaning in the world around them. The veteran possesses past experience, training and education that, when adequately directed and assessed, can translate within academic discourses through higher learning institutions, such as the composition and literature classroom, to students understanding and capability within those fields. Veterans in today's post-war America have access to multiple resources that may assist in their education, employability, and overall transition from service-to-civilian life. Yet, as service people return to the civilian academic and professional workplace in high numbers from active duty, they are often met with unconscious resistance in the form of a society that has no way to compare, relate, interpret, or adequately assist the multi-modal forms 
of literacy learned by the veteran through service. As the scholarship surrounding veteran issues continues through a variety of disciplines - in addition to the discussion of literacies brought to composition classroom by veterans_recognizing the ways by which the multi-literacies of the veteran student came to be suggests that an individual identity as a part of the veteran collective has been formed and will influence the ways in which the individual veteran will interpret the world and create meaning for the rest of their lives. For this reason, a new discourse aimed at guiding our understanding literature and composition through the lens of a common veteran identity becomes necessary within this post-war society.

In this paper I will outline a selection of texts to demonstrate the diverse literacies brought to higher learning institutions by veterans and discuss many of the challenges veterans face when translating these literacies to an in-class instructional setting. I will also identify social disconnections when interpreting the veteran experience through a deficit-based model and offer a preliminary, veteran-centric mode of re-interpretation. By drawing on some key experiences as a Hospital Corpsman having served with the Marine Corps Infantry, I will also attempt to construct a preliminary model for studying the experience of Post 9/11 veterans from an experienced, asset-based point of view. Lastly, in order to broaden the discourse of veteran identity in literature and composition, I will include the brief analysis of three American poems and a brief personal essay exploring an alternate reading of The Great Gatsby, each written to exercise and explore principles of Veteran Identity. It is my hope that the ideas presented in this paper will serve as a jumping-off point for an alternate discussion surrounding a new generation of veterans and what they can bring to higher education institutions, literary theory and the composition classroom.

\section{Identifying Literacy}

In using the term literacy, it is important to keep in mind that 
literacy is not only defined by one's ability to read and write. Literacy can be defined as a much broader interpretation of social values, concepts and interpretations based through individual and collective experience. Brian Street, in his book Literacy in Theory and Practice, defines literacy as "shorthand for the social practices and conceptions of reading and writing." In it, he establishes a theoretic foundation contending that "what the particular practices and concepts of reading and writing are for a given society depends upon the context; that they are already imbedded in an ideology and cannot be isolated or treated as 'neutral' or merely 'technical'" (Street). In other words, the contextual situation informs how we read, write, interpret the world, and create meaning well before we achieve any functionality in them. Consequently, veteran literacy can then be defined as the shorthand for the social practices and conceptions of reading and writing learned from active-duty service within a military institution. While there exists multiple branches of armed service, each containing their own customs, vocabulary and social hierarchy, they are united in a common mission executed through military engagement. For an individual to navigate within a respective branch, they must become inducted in the branch-specific customs, vocabulary and social hierarchy in order to be useful to it. For the veteran, these cultural practices are not easily forgotten after the contract of service has been completed and therefore become a part of the ways by which they read, write, interpret the world, and create meaning within the civilian social body. Additionally, the scope of branch-specific military literacy is so large that it would be nearly impossible to define each aspect within an academic essay in order to situate the reader within general military knowledge, culture, vernacular, traditions, etc. for a branch let alone the whole of military culture. It is for this reason that separating civilian literacy from veteran literacy becomes necessary for understanding how veteran literacy informs veteran identity. 


\section{Identifying the Veteran and Civilian}

For the purposes of this paper it is important to concretely identify who is a veteran and who is a civilian. The veteran may be defined as any person who has served in the armed forces for a period of time (usually exceeding 90 consecutive days, as per DoD) and identifies this period as having any kind of impact on their personal development. Conversely, the civilian in this paper may be defined as any member of the society who has not had this experience. While stating this may be an obvious redundancy, it is profoundly important for this paper that any other sociocultural identifier be engaged within a broader scope of conversation. This binary model serves as a preliminary platform for a wider discussion on other factors in conjunction with the veteran experience. Either by voluntary or conscripted service, all veterans enter into an actualizing environment that has an impact almost as profound as socially interpreted traits from birth. While sociocultural factors such as race, gender, economic status, religious identification, play significant roles on how each veteran experiences life before, during and after their service, further scholarship on this topic is needed in order to explore how service alone impacts the literacies of veterans and how those literacies form a broader identity both independent of and in conjunction with such sociocultural factors.

\section{Conscription vs. Volunteer Service and Possible Social Literacy Disconnection}

In the United States, individual service in the Armed Forces has been informed by the historical predominance of conscripted service such as the draft. For this reason, it is my belief that the cultural consciousness of the country largely shared the responsibility of armed service and therefore shared a cultural understanding of the responsibility of the social body to the veteran community throughout the assimilation process back to civilian life. This is to say that in sharing responsibility, the civilian and the veteran shared a basis for 
interaction with military service and literacy in spite of their vastly different life course.

Since the end of conscription, it has been successfully argued that the quality of service member on active duty has dramatically increased. Service members volunteer and in volunteering have a predisposition to a desired personal outcome or, rather, motivation to complete a period of service (Doe). It is worth noting, however, that since the beginning of the US engagements in Iraq and Afghanistan, active duty service people have experienced an operational tempo (multiple deployments) previously unseen in our country's history (Doe). In terms of literacy and composition, this can be interpreted in a variety of ways, however, the veteran experience of the 21st century at large has been studied and interpreted primarily through injury models and a deficit approach or rather, "What are we/they missing and what do we/they need?" (Cleary and Wozniak).

The eradication of conscription in the US could have caused a major divergence from a common obligation of individual service to a voluntary removal from the society. Further scholarship regarding the relationship of the social responsibility to the Armed Service's pre and post conscription-America is needed to more concretely identify any relationship, if any. But, by imagining conscription as a mode for which the broader social body to connect to the experience, it can also be imagined that conscription in the United States served to share the burden of responsibility of individual service. Again, as stated previously, it has been argued that today's volunteer service-people are more professional, and thus better suited for service, than in decades previous. Additionally, this is not an essay arguing for or against conscripted service in the Armed Forces. It is in identifying the possible modes of disconnection between the veteran and the broader social body that we might be able to better facilitate discourse aimed at bridging the gap between civilian-to-veteran modes of literacy. 
Another possible misunderstanding of the social interpretation of the veteran experience can be cleared up in one empirical observation: not all veterans are veterans of combat. Yet, with an increased number of combat veterans returning to civilian life, particular focus and concern for combat related injuries such as Post-Traumatic Stress Disorder (PTSD) and Traumatic Brain Injury (TBI) often encompass the community as a whole. While continuing the dialogue between care providers and a new generation of veteran patients is crucial to understanding and adequately treating these injuries, perceptions of non-injured veterans tend to take place from an injury-based model. For this reason, the reintegration process for all veterans can mirror the perceived deficiencies of combat veterans to the community at large. There are many reasons for which disclosure of a veteran's experience may be omitted from social dialogue.

In the case of veterans currently being treated for PTSD and TBI, "shame and concern about adverse impact or repercussions prevent disclosure,” and formulate a compelling case for the lack-of-treatment of "moral injury" (Litz). Yet, as Doe states of the in-service literacy of the veteran experience:

One of the most important distinctions among veteran taxonomies also lies in the gulf between combat veterans (those who have deployed overseas and served in a defined combat zone) and non-combat veterans (who may serve stateside or overseas but not in a defined combat zone). While combat experience does not override rank and [jobrelated-specialty], it certainly provides an important filter within the ranks of the military and can change a veteran's sense of his or her military experience and post-military outcomes. (Doe)

This means that often a veterans' in-service self-worth can be dictated by whether or not these experiences or injuries have taken place. Therefore, upon separation, disclosure of the capacity by 
Anthós, Vol. VI, Issue 1

which the veteran served can be equally withheld due to the veterans' perception of themselves as non-combat veterans, reflecting similar feelings of shame and concern experienced by a combat veteran.

\section{Military Literacies and Learning Models}

From the time an individual makes the decision to join the Armed Services, the individual begins an immediate engagement with military culture. In their essay, "Residence Time and Military Workplace Literacies," Sue and William Doe articulate this point: "Induction processes and follow-on military training function as forms of specialized literacy learning that leave a lasting imprint, often becoming central to the identity of the people who experience them" (Doe). Recruitment stations provide the individual with pamphlets and literature that broadly outline aspects of military service as well as training manuals containing some basics of general military knowledge such as nomenclature/cultural vernacular, phonetic alphabet, branch credo, physical fitness requirements, etc. With the imminent knowledge of departure, the recruit is aware that they will soon be engaged in an induction process, generally known as boot camp, where upon completion will render them "a part" of a large organization dedicated on varying levels to war-fighting capabilities. But as a war-fighting agency, this paradoxically marks the beginning of the separation the recruit will experience after induction, throughout active service, departure from active service, and entrance into veteran culture from the society not directly engaged in "war fighting." For the civilian, interaction with a wartime rhetoric is experienced through a variety of media, societal discourse, interaction with veterans, and predominant cultural sentiment. If indirectly engaged with war-fighting rhetoric and lacking intimate knowledge of military culture, the civilian cannot relate in a culturally significant way that compares with that of direct experience and service within the armed forces. 
The primary model for military training and education exists and functions on similar planes as Vygotskyian model, or rather, that individuals develop a cognitive language within the social context of, in this case, military service (Leon). After the initial induction to military life and culture (boot-camp), former recruits, now servicemen and women, move in to multidisciplinary training institutions that will shape an identity within the service member based on a particular profession within the armed services. Some become mechanics, some infantry members, some enter the medical field, but all proceed from the point of initial induction with a subjectively common identity. At the follow-on institution, service members receive an often condensed version of a particular discipline when compared to a civilian counterpart the justification of which is rooted in another important aspect of military training: training is ongoing.

From my time spent on active duty as a Navy Hospital Corpsman, I can recall feeling ill-equipped at performing a lifesaving intervention on a combat casualty after checking into the infantry battalion that I would be serving with for three years. My time in medical training was roughly only two months long. It was after checking in, meeting my supervisors within the medical department (Battalion Aid Station) and constantly being subjected to planned and informal training scenarios from my seniors and supervisors (many of whom had been previously deployed to combat zones) that my skills were refined, my knowledge was expanded and my confidence was increased, giving me the necessary tools to perform adequately under stress. Upon receiving my first casualty in Iraq, it was the on-the-job training provided by my seniors and supervisors that allowed me to make the necessary life-saving interventions for the patient, not the instruction from the postinduction institution. In working in the capacity of a healthcare provider alongside Marine Corps infantrymen, I developed a unique, multi-branch literacy informed initially by the Navy, developed by my supervisors, and executed through the Marine Corps. 
In trying to understand what this means when the veteran continues on to college and to the social body at large, many explanations can be found in the composition writing of veteran students. In her survey of several Marine Corps veterans' selfassessment of writing ability, Corine Hinton outlines key identifiers of the veteran's retrospective applicability of military writing vs. academic writing. One veterans assessment stated "'I need to be able to . . . have every single person who picks up this piece of paper completely understand what I need to do ... and know exactly what I want to accomplish with whatever tasks that I'm trying to set forth'” (Hinton). As a result of her survey, Hinton was able to conclude that most of the Marine student veterans who participated are aware of the ways in which they have evolved as writers. As a result, she outlines four ways by which the veterans understand these connections:

This self-awareness was demonstrated by the Marine student veterans' ability to (1) make connections between previous and current literacy habits or environments without explicit prompt from the interviewer, (2) identify salient points of difference, (3) determine the origin of the changes they identified, and (4) connect those prior experiences and the changes that have occurred to current successes or failures, [or] "critical incidents"-in college-level literacy tasks. (Hinton)

In other words, veterans learn how to effectively tailor their knowledge and/or writing to their audience and to their own rhetorical contexts (Hinton). This is one example of veteran literacies application within the academic institution. Herein lies the foundational principle for veteran literacy: service informs and shapes the ways in which an individual reads and writes. 


\section{The Violence Inherent to Social Bodies and Veteran Understanding}

The institutional violence inherent of a social body can be defined as the violent means by which social bodies either imply or carry out use of force in order to secure particular interest. This is to say that social collectives in action rely entirely upon modes of violence, either to protect, exert or maintain itself. One of the central arguments in the case for veteran identity in literature and composition is the disconnection between the ways in which the civilian and veteran experience and interpret differently the inherent institutional violence. This does not necessarily mean direct engagement with violent acts, themselves, but rather the mode by which a mission is accomplished. The violence inherent, in other words, is the tool by which a mission is carried out and achieved or not. The veteran, through their experience in service of the armed forces, serves an institution dedicated to the execution of, or display of potential for, force of violence. The civilian, it can then be argued (simply by virtue of remaining a citizen of the society for which the violent institution serves) remains compliant to the inherent violence. Individual and collective calls for non-violence or dissention of the institution, by comparison, remain largely unpracticed when considering the breadth and scope of military engagement worldwide. The belief in and practice of non-violence, for example, may be a more righteous approach to matters of conflict dispute when considering humanity yet, historically, massive executions of violence continue to occur on all levels. This means, on some level, that while in service to the institution, the veteran gains a basic understanding of how they serve on a broader scale than the civilian counterpart when engaged in a variety of similar activities that do not involve violence, specifically.

Upon leaving the institution, the veteran must then reenter a society lacking a concept of collective "mission," and may begin to question the validity of knowledge gained through service. This 
begins an ongoing triage process of knowledge gained and assessment of the applicability of said knowledge in the civilian world. While scholarship needs to continue on this topic, it is generally accepted that "the effect of military service on socioeconomic outcomes has varied across time and place," but also that "time spent away from civilian life disrupts the lives of veterans" (MacLean and Elder). In understanding the disruption —and in addressing an adequate strategy for absorption of veterans into the academic discourse-it becomes evident that today's veterans have knowledge to share but are received by an academic model that does not know how to listen.

The transition from military to civilian life can be extremely difficult for the veteran, independent of combat exposure or lack thereof. Many of the literacies gained in service are often untranslatable to a civilian environment yet the veteran feels as though they have knowledge to share. The veteran then begins a triage of knowledge that will serve them in their transition. But as Doe contends, "Leaving the military does not have to mean that the military person must wipe clean his or her identity, but rather that military experience and its attendant literacies can be understood as valuable influences upon the way the veteran thinks and acts in new contexts" (Doe). To illustrate this point, my use of the term "triage" is an example of learned medical vocabulary meaning "to sort." Triage, for the infantry level Hospital Corpsman, is an action that one would perform in a mass-casualty event in order to sort multiple casualties from least urgent to most urgent. It is clear that, in this case, a significant literacy gained through in-service training and experience has been reinterpreted to identify an important personal aspect of my individual reintegration process. Veterans have learned sets of assessed skills that are embedded in the practices of action and responsibility. Doe suggests a situational adaptive quality to the veteran skill set, stating that, "[The] mastery of the military literacies of action and responsibility are always balanced against the conditions on the ground, which rarely present themselves in the perfect form for 
which training may have prepared the service member. [In a combat situation] a person must adapt or perish” (Doe).

Often, veterans are met with resistance in the professional and academic institution finding it difficult to assimilate their literacy to a society ill-equipped to understand their experience. The veteran learns that their connection to the violence inherent is not a valuable asset and the veteran is forced to keep matters of this nature to themselves. As was discussed above, outlets by which to share a once collective experience become limited and the veteran is left to make an interpretation based on previously established hierarchies that may become convoluted through the transition process.

Yet veterans already know how to negotiate multiple expectations when translating their service knowledge to the academic institution. "Document understandability is an important feature that crosses both the academic and military discourse communities” (Hinton). But how can academic institutions adapt to the needs of the incoming veteran population? It is my assertion that the time has come for a lens by which veterans can use their experiences within the military institution and begin to interpret and create meaning of the arts and humanities within the civilian culture in order to broaden the civilian social regard for their collective voice.

\section{Composition and Applying the Veteran Identity Lens}

It should be a common goal within institutions to move away from deficit-based approaches toward the veteran community and start focusing on how veterans can contribute to a robust discourse. Experiences and attitudes formed while in service are unique to the veteran community, yet what is often most lacking is an engaged, civilian society for which to share these experiences. Outside of the veteran community, articulating learning strategies to the civilian becomes problematic for the veteran and often results in silence when called upon to publicly defend skills, literacies or any other gained asset through service. Doe appropriately articulates what is often left 
out by the veteran: "[The] development of military literacy involves learning that never ends. For instance, learning to take action and then taking responsibility for what happens are ongoing lessons, rather than bounded approaches contained strictly within the induction phase or the residence time container known as Basic Training” (Doe).

Veterans are trained for clarity throughout their time in service so, often, clarity is what is expected from the civilian world. "Clearly defined expectations for the writing that faculty expect students to produce was correlative to the Marine student veterans' positive perceptions of composition faculty whereas ambiguity or subjectivity were often correlated with negative perceptions" (Hinton). Additionally, the feedback most generally favored by the veteran participants was that provided by the instructor rather than other students (Hinton).

For Hinton, veterans who were able to identify and then translate previous learning and rhetorical experiences from the military into academic writing contexts reported positive perceptions about that writing. Conversely, "By ignoring what veterans have learned in the military, our society essentially throws away the time and money invested into military training and experience that could be applied to ... the civilian world" (Hinton).

In their essay "Veterans as Adult Learners," Michelle Cleary and Kathryn Wozniak assert that when engaged with the veteran writer it is important for the civilian instructor to be reminded that veterans have already become proficient in specialized discourse communities (Cleary and Wozniak) and outline Malcom Knowles six principles by which adult learners tend to engage with the academic institution:

1. Need to know - adults prefer to know what, how, and why they are learning.

2. Readiness to learn - adults return to school because they have specific knowledge and skills they want or need to learn to solve problems, address challenge or otherwise 
make things happen in their lives.

3. Orientation to learning - adults are focused on learning for doing much more than learning for knowing.

4. Motivated - adults are generally more internally than externally motivated.

5. Self-direction - adults see themselves as and desire to be self-directing.

6. Experienced - the many life experiences of adults are a resource for and sometimes a potential barrier to learning. (Knowles, Holton, and Swanson 63-67)

Given the level of proficiency demonstrated by the veteran through service, instructors 'can use veterans' collaborative inclination both to support veterans in their classes and to value veterans by letting them model or lead collaboration in the classroom” (Cleary and Wozniak). It is in utilizing the previously established modes of veteran literacy and recognizing their unique identity that veterans become a valued participant in the higher education institution. A theory by which to communicate their experience to a social body trying to understand them is certainly worthy of further discussion.

While identifying assets that veterans bring to the academy through the study of veterans in composition settings and trying to understand aspects of how veterans become distanced from the social collective through their awareness of the institutional violence inherent of social bodies does not provide the clearest framework for interpreting literature, it is in writing about them that I believe they were put to work best. As has been mentioned throughout, further scholarship is needed in order to open up the discourse as to the validity and usefulness of veteran identity in literature and composition but the following short essays are submitted as potential examples of putting these ideas to work and exercising their potential. Whether or not they do work within our understanding of the arts and 
letters has yet to be debated but below, numbered 1-4, are a series of textual analyses beginning with three poems and ending with a veteran reading of The Great Gatsby. By including these anecdotal examples it is my hope that some of the content of this paper will become clear and the potential impact of these ideas will be better understood. In including them, these ideas may find a more situated place in the literary theoretical discourse.

1.

A Billy Collins poem, titled "Introduction to Poetry," offers readers an amusing look at the way in which new poetry students engage with the work presented by the narrator. The narrator recounts ways in which they have attempted to guide the students' enjoyment or appreciation of poetry and how the students comically disregard them, succumbed by their need to know "what it means." The poem engages the reader with violence to comic effect through archetypes of Hollywood-stylized police brutality. In this Close Reading, I will reconstruct the texts' poetic intent and authority and will offer an alternative reading through the lens of veteran identity in order to further expand upon the ideas contained in my essay Veteran Literacies: A Case for Veteran Identity Theory in Composition and Literature in hopes of furthering the discourse and its implications on the humanities and literature.

"Introduction to Poetry" uses metaphoric language and situations to present its readers with modes by which poetry (according to the poet) should be read. By asking students to "hold [a poem] up to the light," or "press an ear against its hive," lines one through eleven establish the poet as an authority in the act of reading and engaging a poem. Furthermore, lines twelve through sixteen offer an opposing metaphor as to the way in which students abandon his approach for a violent interaction with the poem. Line twelve through sixteen make this explicitly clear: But all they want to do / is tie the poem up to a chair with a rope / and torture a / confession out of it. / They begin 
beating it with a hose / to find out what it really means. These final stanzas act as a punch line to the previous lines as the metaphorical imagery is in violent opposition of those previous. This is to say that Collins evokes violent acts carried out by, for example, police detectives in movies and/or other narrative media and uses the fictional image to garnish a laugh. In imagining "students" beating a “confession” out of a "poem” Collins relies on the readers association of torture as being experienced indirectly i.e. through movies. While the lines, in working their metaphoric opposition to the previous content, are funny and ironic, relying on fictional depictions of violent acts is a direct reflection of the disconnection to the institutional violence inherent of the social structure.

Collectively, it may be assumed that the average reader of the poem has no literal point of reference with which to interpret something being "tied to a chair," and "beaten.” This is precisely why the juxtaposition to the ways in which the poet wants students to experience a poem and what they do with a poem is amusing. The poems assumption about the reader must be accurate in order to garnish the intended response from the reader i.e. an ironic laugh. Conversely, if the reader had literally experienced an instance of the depicted institutional violence, such as being beaten by a police officer, the intended joke may be read differently. In having experienced an example of institutional violence, the reader now has two ways in which to read the poem: through media proxies depicting violent acts and through the memory of having witnessed real examples of violence. This reader is familiar with the humor at work within the poem and intimately familiar with the nature of the violent acts themselves. Without sacrificing the intended poetics and subsequent humor of the work, it is worth noting that the intended joke becomes more complex when we consider an alternative reading.

There exists a dichotomy in the individual veteran identity and the social identity that they forge after leaving the armed services that mirrors the way in which this alternative reading might gain 
momentum. It is clear that veterans experience an induction through institutional conditioning that remains impactful throughout their lives. Additionally, upon leaving the armed services, the individual veteran enters a social collective not engaged with that institution or the violence inherent in the same way. Therefore, the veteran is forced to triage knowledge and values learned within the institution to adapt to new (and often differing) knowledge and values outside of the service. Their new identity is now not one of a service member nor that entirely of a civilian. They were previously a service member yet don't feel altogether civilian and thus the veteran identity is formed.

As a veteran, my reading of Collins' poem works through two approaches: first, by relying upon proxy-depictions of violence, as stated above, and remaining distanced from emotionally experiencing real violent acts. Having this point of social reference by which to relate the violence depicted in the poem allows me to understand the poetics at work through irony and/or comedy. I can imagine a nameless, faceless student beating a nameless, faceless, bodiless set of words with a hose, demanding a confession. With this reading I am directly engaging my references of pop-culture and their depictions of violence in order to understand what not to do, according to Collins, with a poem. The result is a chuckle.

The second approach is that of an Iraq War veteran who, while conducting a search through the home of known insurgents that became the victims of violent interrogation methods at the hands of Iraqi Army personnel, has witnessed an individual being beaten while tied to a chair. Recalling this literal violent memory is unavoidable as the first approach, with its imagery, leads me directly to the recollection. Again, it is not the poets' responsibility to be aware of all of the ways in which people experience violence and to be sensitive to that by not evoking the images. In fact it the case is quite the contrary. In this case, it is precisely the poets' use of and reliance upon the proxy-violence throughout pop-culture that calls his poetic authority into question. 
Collins professes an expertise in how poetry should be read. This is evident in in the first eleven lines through his description of the ways in which he asks his students to treat a poem. This is also evident as the poem is an artifact having been created. Collins, in writing the poem, is responding to an exigency he sees in his classroom the he believes needs correcting. Through the application of humor and use of proxy-violent imagery, Collins, as the expert of poetry in this way, is offering what he believes to be the better approach to reading a poetic work. Yet the use of proxy-violent imagery shows that, in the instance of the poem, he is either deliberately or unconsciously disconnecting the reader from explicit and real acts of violence. As a proxy, the violent acts lose their severity and are allowed to become comical. Yet, as a veteran having witnessed severity of this nature, I am placed in a position of acknowledging the humor of the poem over the violent memory it recollects in order to experience the poetics with my peers who have not witnessed similar violent acts. The social disconnection of the institutional violence inherent is, thus, allowed to continue and discussing their literal implications on our collective consciousness becomes more difficult. As a veteran and a student of poetry, I may or may not wish to share these experiences in an open setting. Either way I am placed in a position to recall a violent memory, decide the applicability of my experience in context of the poetics, and triage that knowledge within the social context that places me, the veteran, as a conscious minority within the classroom setting. It is here that we see the veteran identity begin to inform this reading of Collins. The result is that Collins' expressed poetic authority diminishes through the use of proxy-violent images and serve to widen the gap between the civilian social body and their capability to interact with the violence inherent in a meaningful way thereby lessening their capacity to understand the veteran experience in a meaningful way.

The responsibility of the disconnection is not on Collins, however. Collins relies on pop-culture as a proxy and the proxy has 
existed well before this poem. Collins' co-opting of the proxy as a device for the poetics is only a reflection of his own naivety toward violent acts and a promulgation of social disconnection to the institutional violence inherent of the greater social body. In other words, Collins' use of violence works as a buffer between the reader, the institutional reality of violent acts and how each work together to distance themselves from each other. In this reading, "Introduction to Poetry” positions itself to further disconnect individuals from the institutional violence inherent of the social collective by embracing a complicit ignorance to it.

2.

Robinson Jeffers's poem "Hurt Hawks" is a glimpse at the relationship the narrator maintains with the spiritually divine, nature and himself by using the anecdote of a euthanized hawk. In order to illustrate the narrator's authority on matters of mortality, the poem recounts an injured hawk that is cared for, set free, it returns, and is ultimately killed. While a problematic and contradictory narrative often emerges in this poem, this work, nonetheless, continues to be read and discussed in spite of, or perhaps because of, these contradictions. In this close reading I will attempt to outline ways in which Jeffers complicated narrative serves to justify the violence inherent of social bodies through its dependence on certain philosophical tropes and use a veteran identity model for interpreting and reevaluating the poetics and what they want from the reader. By focusing on the second stanza while supplementing lines from the first in order to situate the reading, I hope to show ways in which the narrator serves the institutional violence inherent of the social collective by justifying a singular act of violence admittedly carried out. "Hurt Hawks" works to abandon the philosophical trope of what separates man from beast is man's knowledge of his own mortality. The poem is explicitly constructed around the narrator's observation of an animal, a hawk, consciously aware of its impending death and 
hope of deaths expedited arrival. The narrator attempts to separate himself from the trope, as well as the social collective, in lines thirteen through fifteen:

The wild God of the world is sometimes merciful to those That ask mercy, not often the arrogant.

You do not know him, you communal people, or you have forgotten him;...

Here, the narrator suggests that his familiarity with the natural and divine is achieved through a deeper connection to the "wild" and that those living communally, presumably in cities, do not have this connection and have therefore lost their connection to the "wild God."

The narrator uses his connection to the natural divine to establish authority when abandoning the aforementioned trope and exercises this authority first explicitly in line ten: "The curs of the day come and torment him."

Here, with the narrators authority established and in interpreting the "curs" of a natural existence because he is a part of it, we see that this connection to the hawk is greater than what "communal dwellers" could achieve and is professed as more accurate. Additionally, with line sixteen the narrator enters the mind of the hawk to assert that, "the hawk remembers [the wild God.]"

In abandoning the man/mortality trope, the narrator is engaging with nature in a way he believes separate and superior to the social collective. This is the principle mode of justification for the euthanasia of the hawk throughout the second stanza. He sets up a scenario where the reader is expected to trust the narrative judgment regarding the fate of the hawk and finishes with how the hawks fate was carried out through qualifying language further underlining the narrative disconnection to mankind. Yet, even while attempting to distance himself from the collective, the narrator brings our attention back to his own subjectivity to the social collective in the same 
sentence. He continues his distancing by showing the reader that men mean less to him than hawks and the reader is left with further evidence of the narrative authority in natural matters. Yet, the narrator cannot escape the collective. The first line of the second stanza illustrates this point: "I'd sooner, except the penalties, kill a man than a hawk;..."

Here we can see the narrative subjectivity to the social collective because the narrator acknowledges if he were to kill a man he would be penalized and so he does not kill men. The narrators attempt to become wholly distanced from the social collective is now limited to his adherence to laws governing the social collective through penalties. This means that the narrator is also aware, albeit loosely, of his ultimate subjectivity to "communal people," and the laws governing them as well as himself. This mildly undermines his poetic authority by showing the reader how difficult it is for man to live in pure harmony with the natural divine.

As the second stanza progresses by exploring the narrators professed connection to nature through reading the hawks thoughts and/or cues, so does the narrative reliability fall into a deepened ambiguity. The narrative continues to assert that the hawk is aware of its own mortality and is actually, in line five, "asking for death.” Yet, despite this professed connection to the natural, or "wild God," in remaining compliant to the laws and penalties set forth by the social collective, in this case "communal dwellers," the narrator is also complying with the collective motivation. Otherwise why not kill a man, penalties be damned?

The narrator uses a rhetorical mode of separation from the social collective to convince the reader of his natural superiority yet still remains complicit to its laws. The death of the hawk for this reason is just another way in which the narrator paints himself into a rhetorical corner by exercising his own violent will over nature and attempting to justify it to the reader. In identifying the modes of contradiction provided by the narrator, we can now begin to explore how this act of 
violence and its subsequent justification are a key example of narrator's blindness to his participation in the violence inherent of social institution.

It is important to also note the way in which the narrator carries out the violence. The hawk was put to death with a bullet: a manmade explosive projectile explicitly developed for purposes of killing. By the narrator's logic, a more natural way for the hawk to have died would have possibly been at the bare hand of the narrator rather than an explosive projectile. Guns and bullets are used the world through to carry out violent acts against mankind as well as to exercise man's dominance over nature. To buy, possess and operate a weapon of any kind is to contribute to their creation, justification and subsequent application in a variety of theaters. If the narrator were to truly engage with nature in the meaningful way he suggests by delivering death to an animal aware and begging for its mortality, then it is not unreasonable to speculate whether or not using his hands without a weapon would have been a more natural and/or intimate mode of execution.

Lastly, the narrator twice brings out attention to arrogance: first, in line 14 of the first stanza and lastly, in line seven of the second stanza. Each instance, arrogance is projected onto a subject that is not the narrator as follows: God does not show mercy to the arrogant and that the hawk, in asking for death, is exhibiting arrogance. Yet if it is the "communal people" that, who in losing touch with the "wild God," reveal their arrogance over nature, then the narrators mechanized execution of the hawk is yet another example of his own delusions-of-disconnection from the social body. In other words, killing the hawk is an arrogant act complicit to the social violence inherent of the collective body completely unrealized in the text.

While the contradictions of this text are many, the narrator continues to remain comfortably unaware of how his actions, and recital of those actions in verse, remain entirely complicit to the modes of a greater social body and the subsequent violence inherent 
of its creation and maintenance. The narrator is a man who follows social laws and violently carries out his projected will over a creature through a social weapon and justifies it through a rhetoric that presumes an audience deficiency in understanding his professed authority. Through the veteran identity reading, it becomes more likely that Jeffers' contradictions within the work diminish his poetic authority serving to widen the gap between the civilian social body and their capacity for interaction with the violence inherent of social bodies.

\section{3.}

Adrienne Rich's poem, “Ghost of a Chance,” takes a gendered stance toward the evolution of mankind by focusing the reader's attention toward men and their attempts to move humanity forward through thinking. While the narrator makes clear in the text that she regards men to be incapable of "real" thought, what she is suggesting is that the gendered imbalance of power structures has not served mankind in a constructive way. For this reason, the narrator is taking a direct stance in opposition of the male-dominant social hierarchy as a response to the violence inherent of the social body. In this close reading, I will examine the elements by which "Ghost of a Chance" opposes the gendered hierarchies of the social collective and use veteran identity theory to examine how the poem responds to the exigency of violence-inherent in order to extract modes by which the narrator is resisting complicity to it.

Before beginning this reading it is important to identify what the violence-inherent is (something I do not recall defining in my foundational essay, though that will soon be corrected.) For purposes of this argument, the social violence inherent of the institution can be defined as any collective body of individuals who, by implied or applied means, exert authority, either deliberately or unconsciously, through expressed violent means. While reading "Ghost of a Chance," the oppressing institution of men over women is the exigency by 
which the poem is responding and, therefore, the violence-inherent is expressed in a gendered fashion and personified unequivocally by men.

We are shown in the first and only two lines of the first stanza that narrator does not regard a man as capable of actual thought: "You see a man trying to think."

This is an assertive and direct image. The stanza dictates what we see. There is no subjective allusion to these lines such as "When I see a man..." or "If you see a man." The image is ordered upon our imagination and commanding the reader, ordering the reader, forcing the reading to see something and in no way engaging in the pleasantries of invitation.

The next thing to notice in the lines is that the subject is singular and gendered. This is following along with the assertive nature of the language by forcing an unambiguous singular-masculine presence of “a man.” Again, in no way is our subject a woman, animal or anything other than "a man."

Beginning on the second line, the assertive and forceful language imagery continues as a necessary mode of communication but perhaps engages and/or plays with presumption. "Trying," can be read in two ways: one, that who/whatever is forcing the imagery upon the reader is also inside the subjects' (a man) mind and can recognize that the subjects attempted engagement is not so adequately engaged as to deserve being call "real" thought. Two, that who/whatever forcing the imagery is intending to be patronizing of the subject thereby engaging outside of the non-subjective boundaries it initially sets. In other words, the poem assumes a superior role to the subject and defers "thinking” to "attempting to think." Either way, however, the poem asserts its superiority to the subject in its ability to determine what is "real thought" or "thinking" and what is not. Here, the subject is clearly not engaging to the poems standards of thought.

Identifying the subject as a gendered entity becomes important because, without it, the following stanza can read like a generalized 
condition of a greater social collective. The poem offers less assertive images (like a fish, almost crawling, etc.) in the second stanza with the same presumptive and/or patronizing quality while utilizing another set of evolutionary images. With the inferior, gendered subject it could be easily expected that, as an oppositional quality, the poem itself is female, woman, feminine, etc. As the poem progresses, what emerges is an indictment of masculine power and the subsequent violence-inherent through the questioning of its usefulness to the collective social progress, or rather, violence is still expected. The last three lines make this clear: "till a wave pulls it [a fish] back blind into the triumphant sea."

The science (evolution in this case) of the poem lends itself the authority to assert that masculine intelligence, or violent intelligence, is nothing more than an attempt at intelligence providing evidence of the fish blindly washing back into the ocean as proof. Furthermore, because of the established authority of the feminine in opposition of the masculine attempt at thought (trying to think, terrified, the old consolations, almost breathing, blindly, etc.) the poem suggests that without the "thoughts" of men, the broader social collective would be farther along the evolutionary food chain, or rather, not accepting the violent inherent. The "true/real" feminine thought is what is superior and what will not continue in this similar, painful repetitive process further reinforcing collective social compliance to the violence inherent.

Through the use of assertive language, gendered opposition and evolutionary images, the violence inherent of the greater social collective, to the poem, only exists because men remain primarily in control of large social matters. The poem, in this way, forces readers to consider whether or not violence would remain inherent if women dominated control over these greater social matters. Additionally, the poem uses assertive language as a utility finding it necessary to be heard by the socially dominating and oppressive gender through its use and disregarding the application of passive language possibly 
believing it inadequate due to its intent. With men as the personified violence inherent, "Ghost of a Chance" is attempting to abandon complicity to the dominant social collective and violence inherent by dismissing it, also, as inadequate to the greater social body.

\section{4.}

In F. Scott Fitzgerald's The Great Gatsby, Jay Gatsby was an insufferable romantic. He believed at the heart of his being that he and Daisy should and would be together and constructed a complex world around him in order to make that happen. Gatsby's romance became a delusion that, through the course of complicated circumstance, led to his death and an unrealized dream of constructing a life with the object of his obsession. There has been a great deal of discussion surrounding Gatsby's contagious personality and conviction-ofpurpose but not enough dealing with how his fatal romantic tendencies came to be. Granted, his backstory is given to us in sections. First, he tells us a lie and next he, presumably, tells us the truth as it is mildly corroborated by Daisy. Yet, even learning of Gatsby's coming-of-age story, the conversation about how he came to be such a fatal romantic has been largely unexplored. Most of my experience in discussing the romance of Jay Gatsby in and out of the classroom has relied heavily on the presumption that he is just that way. What I wish to explore in my final essay is a possible catalyst for his romantic tendency as having either began during, or being exacerbated by, his time in the service. In developing this idea, I will rely entirely on my own experiences while serving with an infantry battalion of the US Marine Corps and explore ways in which being disconnected from the civilian lifestyle lead me to fantasize about how life would be when I returned home and how those fantasies, more-often-than-not, were in contradiction with the outcome after my return. Additionally, by engaging with memories of my own time-inservice and identifying ways in which those experiences shaped my individual identity, I am putting a few of the foundational principles 
of veteran identity theory to work within this immensely important and culturally historical text. In not offering any supplemental literature behind veteran identity theory, I am simply gauging the ways by which my own experience in the military has given me cause to notice certain aspects of Gatsby's character and interpret it in an alternative way.

In the novel, we are made aware that Gatsby had come from humble means and met Daisy at a party while serving in the US Army shortly before World War I. He was deployed to the European front and the couple became estranged. It is my assertion that, in being away from a civilian society and being placed in a stressful set of circumstances, this was the period by which Gatsby's romantic fantasies about Daisy and their future life together began to cultivate. Before deploying aboard the USS Juneau early in my enlistment with 2nd Battalion, 5th Marines out of Okinawa, Japan when I was twentyone years old, I had met and begun a romance with a girl from Southern California. We met at a party where she approached me and we engaged in good conversation. We exchanged numbers and later got together for meals and drinks and eventually we became lovers. The romance was strained, however, by the knowledge of my imminent departure with the military to Japan for service aboard a ship. After we had met, there were approximately three weeks before I was slated to leave. For this reason we spent as much time together as we could and frequently stayed the night together in order to continue enjoying what we both felt, whatever that was, about each other. It was never made clear by either party that maintaining our romance was something we would attempt to do while I was away. I was afraid that she would say she didn't wish to and, in receiving an answer I didn't want, afraid it would negatively affect our short, remaining time to spend with one another. Although I could never speak definitively for her, I always believed that she understood that feeling as well and, in spite of knowing I would be away, avoided the subject for the same reasons. It was understood that the deployment 
was to be approximately nine months long and that seemed, to us as young lovers, like an unreasonably long time to remain committed having only known one another for a few weeks. I was doubtful about the outcome and tried to reside to the fact that she may not feel the same way about me after that period of time.

The day came to leave and I left. I flew to Okinawa, boarded a ship and remained at sea for long stretches without modern and/or accessible means of communication. There were computers and phones whose service and accessibility was unreliable as well as mail service but after a month or so our correspondence became less and the likelihood of reuniting with the same romance became, logically, less as well.

Life aboard the ship was not exactly difficult. Routines were established and work continued, however, being away from a normalfeeling life became difficult. I began to miss things: fast food, beer, the radio, bars, cars, romance, you name it. Anything that I desired but did not have accessible began to take on an inner reverence and later romantic entity almost entirely because I could not have it. So, too, did my memory of the girl I had met slowly begin to turn into a narrative of my future. I can recall, many times, laying in my rack (bed) listening to music through headphones and imagining what life would be like when I got home. She would be waiting on the parade deck and kiss me in front of all my fellow service members. I would run my fingers through her hair and she would kiss me on the corner of my mouth the way she did before I left. We would be allowed to spend time together again. I would meet her family. Her mom would love me because I knew how to flatter her and make her laugh. Maybe, after my enlistment was over, her dad would give me a job in that business he had. She and I would get married on the beach and live together in Orange County and vacation in southern France where we would tell friends and acquaintances of how we met only three weeks before I had to leave for nearly a year. We would have a daughter. She would have sharp, blue eyes and we would name her 
after a song we both liked and we would not paint her room pink because neither one of liked the idea and I would tell her stories of what Southeast Asia was like and on and on and on...

None of this ever happened. I came home and she was in college in a different city. Aside from the occasional email we rarely spoke and then we both drifted into each other's respective memorycollective independent of one another. But imagining this situation and many others like it was a welcome mental vacation from the reality of having to long for the things I could not have aboard that ship. The fantasy made the reality more manageable somehow and was, therefore, an important thing to do.

In 2007, while serving with the same unit, I deployed to Ar Ramdi Iraq and I had married the year before my departure. Similar to the previous deployment aboard the ship, I was again, subjected to the longing and desire for those things, physical and emotional, that I could not have. What became different, and more profound, was that this time I was residing in a country at war and was directly contributing myself to that war effort. It was a decidedly dangerous place to be and we were all conscious of that danger. With or without direct engagement of an enemy, existing in a place of dangerous reality has an effect on the emotional make-up of the individual imagination. Being aware that, at any time, something bad could happen to you or a friend is something that you have to accept and that knowledge, however useful, can become stressful.

Within the boarder of a stressful environment I can remember that the fantasies I regularly used to cope with the present reality became even more rampant. Those who you expected to be waiting for you back home became more important. Letters became more coveted and the threat of broken romantic commitments became more devastating. While I did not experience this (my wife never gave me cause to suspect our commitment to one another was in jeopardy, on the contrary, she made every effort to communicate through limited means and, through words and action, supplied me with the 
confidence that she would remain my everlasting partner while recently celebrating our seventh wedding anniversary with our oneyear-old son,) I had witnessed and sympathized with many familiar faces when their commitments of their romances had succumb to the stresses of separation. It had a maddening effect on those who experienced it. Living a stressful present combined with the loss of trusted emotional support and confined by the inability to change anything about the outcome often made for an explosive combination. Even our realities (home, family, possessions) were subjected to the wild imaginations of these service members, myself included. While sitting in the home of an Iraqi family late at night during a patrol, I can remember telling my fellow service members about what I was going to do when we got home. I said I was going to buy a trailer R.V. and pick-up to tow it. My wife and I were going to reside at a beachfront campground that I knew about and save money to buy a swanky restaurant. The name of our restaurant was going to be “Cha'lie's: Where it's ladies night every night.” My wife would serve and bartend while I worked the floor and occasionally entertain the crowd with stand-up comedy. On special occasions, the jazz trio I played percussion with (also something I was going to start after returning home) would play mellow tunes to customers and if you brought a military I.D., you got a free drink on the house. Even better, if you could prove to me that you had served with Fox Company (our company), you could drink for free. We all liked the idea.

In addition to emotional vulnerability I can recall witnessing and mildly experiencing while deployed, I can also not remember a time ever in my life where sexual desire had run so rampant. Far more elevated than while aboard the ship, thinking and talking about sex dominated such a major portion of our collective consciousness than would seem to be reasonable outside of that environment. Never before or since had masturbation, either in conversation or practice, become less socially taboo while techniques, methods, private places, arousing material, etc. were openly shared, discussed and encouraged. 
All of this is presented to suggest that the fantasy consciousness of the actively engaged service member plays an incredibly significant role on how to cope with the unpleasant, often dangerous, present reality. The fantasies occupied such an important place in my emotional wellbeing that to have them threatened or taken away would have been devastating.

As one could assume, few of my return-home fantasies were ever realized. I never lived on the beach in an R.V., I rarely save money, I don't own a swanky restaurant, and I don't play percussion in a jazz trio. While I am still happily married, the retrospective thought of my wife not being on the parade deck to kiss me when I got home is almost more than I ever want to imagine even though, in reality, she was. I know that, because my expectations regarding my shared romantic commitments were not betrayed, I did not have to undergo the emotional pain of losing the object of my desire while experiencing a period of heightened stress.

While Jay Gatsby may have let his romantic fantasies take over to a fatal end, through this reading it is not unreasonable to expect that a portion of their emotional connection to him was either generated during, or exacerbated by, his time serving on the European front of World War I. His expectations and the subsequent plans he had made to justify them, were solidified through having undergone an incredibly stressful period void of the desired social, physical and material contact that come to be regarded as necessary to feel human and "normal." I needed my complex romantic fantasies while deployed to a combat zone. I can imagine Gatsby needed them too. In the end, however, I got the girl, though I can imagine it being just as devastating if I hadn't.

\section{Conclusion}

While these ideas remain in need of sustained conversation and scholarship, it is my hope that this paper may serve as a platform for a much needed conversation to begin surrounding the veteran 
experience of the 21st century and arouse questions about this experience. Often we engage with outlets that address issues facing veterans upon transition from military-to-civilian life without engaging the veteran community's voice. Additionally, education within the higher learning institution after military service has become a central place for veterans to begin their transition. They bring a great deal of knowledge with them to these institutions but, as what I hope has been worth some serious consideration, are left with few outlets to share, translate, or otherwise be understood by the civilian social body that wishes to interact with their experience in a meaningful way. For this reason, I believe it is time for the civilian social body to reevaluate the ways in which they serve or remain complicit to the violence inherent in social bodies, and to ask what assets and experiences do veterans bring to the table. If this conversation can begin and sustain, it is my belief that veteran identity theory in literature and composition courses will offer a new voice in the humanities, literature and composition. A new generation calls for a new generation of ideas.

\section{Works Cited}

Cleary, Michelle Navarre, and Kathryn Wozniak. "Veterans as Adult Learners in Composition Courses.” Composition Forum Vol. 28, Fall (2013): 1-15. Web. 5 Mar. 2014.

Doe, Sue, and William W. Doe. "Residence Time and Military Workplace Literacies.” Composition Forum 28 (2013): 2-12. Web. 5 Mar. 2014. Hinton, Corrine. “'The Military Taught Me Something About Writing': How Student Veterans Complicate the Novice-to-Expert Continuum in Fist-year Composition.” Composition Forum 28, Fall (2013): 4-16. Web. 9 Mar. 2014.

Knowles, Malcolm S., Elwood F. Holton, and Richard A. Swanson. The Adult Learner: The Definitive Classic in Adult Education and Human Resource. Boston: Elsevier. 1973. Print.

Leon, Kendall. “Activity Theory.” ENG 414/514: Composition Theory.

Portland, Oregon. 3 Feb. 2014. Web. 9 Mar. 2014.

Litz, Brett T., et al. "Strategy, Moral Injury and Moral Repair in War Veterans: A

Preliminary Model and Intervention.” Clinical Psychology Review 29.8 
Anthós, Vol. VI, Issue 1

(2009): 695-705. 5 Mar. 2014.

MacLean, Alair, and Glen H. Elder. "Military Service in the Life Course.” The Annual Review of Sociology 33 (2007): 175-195. Web. 5 Mar. 2014.

Street, Brian. Literacy in Theory and Practice. Cambridge: Cambridge

University Press, 1984. 